\title{
Early Diet Dilution with $40 \%$ Rice Hull Induces Lower Body Fat and Lipid Metabolic Programming in Peking Ducks
}

\author{
Xiao Yang Guo, Yong Jun Fang, and Ling Ying Wu* \\ Department of Animal Science and Nutrition Engineering, Wuhan Polytechnic University, \\ Wuhan, Hubei 430023, P. R. China
}

\begin{abstract}
This study was conducted to evaluate the effect of early diet dilution with $40 \%$ rice hull on growth performance, carcass characteristic and composition of meat-type ducks, and to reveal the possible mechanism for decreased body fat deposition. 160 1-day-old White Peking ducks with initial body weight of $44.5 \pm 1.0 \mathrm{~g}$ were allotted to two treatments with 8 replicate pens per treatment and 10 ducks per pen ( 5 male and 5 female). Ducks were fed with the experimental starter diets diluted with $0 \%$ (control, RH0), $40 \%$ rice hull (RH40) during 8 to $14 \mathrm{~d}$ of age, respectively. Thereafter, all ducks were fed with grower diet. Ducks fed with RH40 diet from 8 to $14 \mathrm{~d}$ of age increased $(p<0.05)$ feed intake, decreased $(p<0.05)$ body weight, body weight gain and adjusted feed intake (excluded rice hull), abdominal fat, skin with fat, and fat content in carcass, and reduced $(p<0.05)$ activities of hepatic malic dehydrogenase, glucose-6-phosphate dehydrogenase and fatty acid synthetase. When diet dilution was withdrawn in the re-fed period from 15 to $42 \mathrm{~d}$ of age, full compensatory growth of body weight, breast meat and leg meat weight were attained. However, ducks were still less $(p<0.05)$ carcass fat content and showed continually lower $(p<0.05)$ hepatic lipogenic enzyme activities at the market age in RH40 ducks than the control. These results indicated that diluting diet with $40 \%$ rice hull during 8 to $14 \mathrm{~d}$ of age might be a suitable method to improve feed efficiency, and to reduce carcass fat deposition in the production of meat-type ducks.
\end{abstract}

Key words: carcass composition, ducks, early diet dilution, growth performance, hepatic adipose enzyme activity

\section{Introduction}

At market age, Peking duck carcasses contain up to $30 \%$ of fat (Leeson et al., 1982). Excessive fat results in not only a poor feed conversion, high cost of production and inefficiency production, but also an undesirable marketing reflection due to health concern of consumers (Knizetova et al., 1991; Plavnik et al., 1982). Therefore, improvement in carcass quality by decreasing carcass fat deposition has become a hot topic in meat-type duck production industry.

Several studies have shown that early feed restriction could decrease fat content and increase protein deposition in carcasses, thus resulting in the improved carcass composition in broiler chickens (Jones and Farrell, 1992; Nielsen et al., 2003). Many investigators had attributed such results to lipogenic responses (Rosebrough et al., 1986),

\footnotetext{
*Corresponding author: Ling Ying Wu, Department of Animal Science and Nutrition Engineering, Wuhan Polytechnic University, Wuhan, Hubei 430023, P. R. China. Tel: 86-27-8395-6175, Fax: 86-27-8395-6175, E-mail: xiaowlying@163.com
}

and control of hyperplasia and/or hypertrophy of adipocytes (Zhong et al., 1995; Zubair and Leeson, 1996). Metabolic programming may be defined as a physiological process whereby early adaptation to a nutritional stress permanently changes the physiology and metabolism of the organism and continues to be expressed even in the absence of the stress that initiates it (Lucas, 1998; Patel and Srinivasan, 2002).

Among various feed restriction regimens, researchers noted that diet dilution at early age have an advantage for practical application and is a rather easy way to induce growth retardation and meet the requirement of animal welfare (Hassanabadi and Nassiri Moghaddam, 2006; Rezaei et al., 2006). Furthermore, to the best of our knowledge, there was no report conducted to investigate the relationship of feed regimen and body fat content and metabolic programming in meat type Peking ducks. We hypothesized that diet dilution may also responsible for the decreasing of body fat content of meat type ducks and changing the metabolic programming, as previously mentioned what had happened in broilers (Jones and Farrell, 1992; Nielsen et al., 2003). Thus, we conducted this trial 
to examine the effect of early diet dilution with rice hull on growth performance, carcass characteristics and composition, activities of hepatic lipogenic enzymes and lipid metabolize programming in Peking ducks.

\section{Materials and Methods}

The protocol of current study was reviewed and approved by Hubei Province Institutional Animal Care and Use Committee.

A total of 160 1-day-old White Peking ducks provided by the local commercial hatchery (Wuhan Chunjiang Poultry Co., Ltd., China) were randomly allotted to two treatments with 8 replicate pens per treatment and 10 ducks per pen ( 5 male and 5 female). Ducks were raised in $200 \times$ $120 \times 70 \mathrm{~cm}$ (length $\times$ width $\times$ height) pens with wire floor. The light regime was set at a $23 \mathrm{~h}: 1 \mathrm{~h}$ light-dark cycle. The temperature of the house was set at $32^{\circ} \mathrm{C}$ and a $1{ }^{\circ} \mathrm{C}$ decrement every two day was applied until it reached $22^{\circ} \mathrm{C}$ and then maintained this temperature. During 1 to $7 \mathrm{~d}$ of age, basal starter diet was given to all ducks. Ducks were fed with the experimental starter diet diluted with $0(100 \%$ starter basal diet $+0 \%$ rice hull, $\mathrm{RH} 0$ ) and $40 \%$ rice hull ( $60 \%$ basal diet $+40 \%$ rice hull, RH 40 ) from 8 to $14 \mathrm{~d}$ of age. Thereafter, ducks were fed with identical basal grower diet up to $42 \mathrm{~d}$ of age. All basal diets were formulated to meet the nutrient requirements according to NRC (1994) (Table 1). Birds were fed ad libitum access to feed and fresh water.

Ducks were weighed at $7 \mathrm{~d}, 14 \mathrm{~d}$ and $42 \mathrm{~d}$ of age, and feed intakes were recorded daily based on replications. Body weight gain (BWG), feed intake (FI) and feed : gain ratio $(F: G)$ were calculated according to these data. No mortality was observed throughout the experimental period.

At $14 \mathrm{~d}$ and $42 \mathrm{~d}$ of age, 16 ducks per treatment (1 male and 1 female per pen) with similar body weight to the pen average body weight were euthanized by decapitation. The liver was carefully removed immediately, and was quickly snap-frozen in liquid nitrogen, and then stored at $-80^{\circ} \mathrm{C}$ for subsequent analysis.

At 14 and $42 \mathrm{~d}$ of age, 16 ducks per treatment were used for carcass analysis. After feed deprivation overnight, 2 birds ( 1 male and 1 female) were selected randomly from each pen, individually weighed, sacrificed by cervical dislocation. After thoroughly bleeding, the carcasses were plucked and eviscerated manually. Abdominal fat (including mesentery fat), breast meat (including pectoralis major and pectoralis minor), leg meat (including thigh and
Table 1. Ingredient composition and nutrition levels of the basal diet (as fed) ${ }^{1}$

\begin{tabular}{lcc}
\hline \hline \multicolumn{1}{c}{ Ingredient, g/kg } & $\begin{array}{c}\text { Starter } \\
\text { basal diet }\end{array}$ & $\begin{array}{c}\text { Grower } \\
\text { basal diet }\end{array}$ \\
\hline Corn & 582.3 & 654.3 \\
Soybean meal & 361.7 & 284.0 \\
Soybean oil & 20.3 & 26.6 \\
Limestone & 12.0 & 12.0 \\
Dicalcium phosphate & 14.0 & 14.0 \\
Sodium chloride & 3.0 & 3.0 \\
DL-Methionine & 1.7 & 1.7 \\
Choline chloride, 50\% & 1.0 & 1.0 \\
Vitamin and trace miner premix ${ }^{2}$ & 4.0 & 4.0 \\
\hline Total & 1000 & 1000 \\
\hline Calculated compostion & & \\
ME ${ }^{3}, \mathrm{MJ} / \mathrm{kg}$ & 12.13 & 12.55 \\
Crude $\mathrm{protein}, \mathrm{g} / \mathrm{kg}$ & 210 & 180 \\
Methionine, g/kg & 5.0 & 4.0 \\
Cystine, g/kg & 3.6 & 3.2 \\
Lysine, g/kg & 11.0 & 9.0 \\
Calicum, g/kg & 8.8 & 8.6 \\
Nonphytate phosphorus, g/kg & 3.9 & 3.8 \\
\hline Analyzed composition & & \\
Crude protein, g/kg & 206 & 185 \\
Methionine, g/kg & 4.9 & 4.1 \\
Cystine, g/kg & 3.7 & 3.3 \\
Lysine, g/kg & 10.8 & 9.2 \\
Calcium, g/kg & 8.6 & 8.4 \\
Phosphorus, g/kg & 0.38 & 0.37 \\
\hline & &
\end{tabular}

${ }^{1}$ Starter phase, d 1-14; Grower phase, d 15-42.

${ }^{2}$ Content of vitamins and minerals in diet per $\mathrm{kg}$ are as follow: 8,000 IU retinyl acetate; 3,000 IU cholecalciferol; 20 IU DL- $\alpha-$ tocopheryl acetate; $2 \mathrm{mg}$ menadione sodium bisulfite; $1.5 \mathrm{mg}$ thiamin mononitrate; $8 \mathrm{mg}$ riboflavin; $3 \mathrm{mg}$ pyridoxine hydrochloride; $0.02 \mathrm{mg}$ cobalamin; $10 \mathrm{mg}$ calcium-D-pantothenate; $50 \mathrm{mg}$ nicotinic acid; $1 \mathrm{mg}$ folic acid; $0.2 \mathrm{mg}$ biotin. $\mathrm{Cu}$ (as copper sulfate), $10 \mathrm{mg}$; $\mathrm{Fe}$ (as ferrous sulfate), $60 \mathrm{mg}$; $\mathrm{Mn}$ (as manganous sulfate), $80 \mathrm{mg}$; $\mathrm{Zn}$ (as zinc oxide), $60 \mathrm{mg}$; I (as potassium iodide), $0.2 \mathrm{mg}$; $\mathrm{Se}$ (as sodium selenite), $0.3 \mathrm{mg}$.

${ }^{3}$ Calculated according to the AME of chickens (Ministry of Agriculture of China, 2004).

drumstick), and skin with fat were excised manually and weighed, and then returned to the carcass. The eviscerated carcass with gastrointestinal tract (washed away digesta with $0.9 \%$ cold sodium chloride solution) and viscera, except for blood, digesta and feathers, were weighed and frozen at $-30^{\circ} \mathrm{C}$ until further composition assay.

All weights data, including eviscerated carcass, breast meat, leg meat, skin with fat, and abdominal fat, were expressed as a percent relative to live weight before slaughter.

The moisture, crude fat, crude protein and crude ash contents of eviscerated carcasses was analyzed according to the method of AOAC (1984). 
Liver were pre-treated according to method described by Tan and Ohtani (2000). The hepatic activities of malic dehydrogenase $(\mathrm{MDH})$, glucose-6-phosphate dehydrogenase (G-6-PDH), and fatty acid synthase (FAS) were determined according to the methods described by Colowick and Kaplan (1955), Bergmeyer et al. (1974), Gibson et al. (1972), respectively. Protein concentration of solutions used for enzyme assay was determined by Coomassie brilliant blue method using protein assay kit (Nanjing Jiancheng Technology Co., Ltd., China). Enzyme activities were expressed as nano-mole of NADPH production (MDH and G-6$\mathrm{PDH}$ ) or NADPH consumption (FAS) per min per $\mathrm{mg}$ protein at $37^{\circ} \mathrm{C}$.

All data were statistically analyzed by a one-way ANOVA using the GLM procedure of SAS (2000) as a completely randomized design. Results were expressed as the SEM. Probability values less than 0.05 were considered significant.

\section{Results and Discussion}

Feed restriction has been well investigated in poultry production to improved the feed efficiency and decreasing the breeding cost (Zubair and Leeson, 1994). Although early feed restriction reduces growth performance, compensatory growth in the re-feeding period will be attained to acceleration organism growth to reach the normal weight (Hornick et al., 2000). Tan et al. (1999) reported that fully growth compensation at $47 \mathrm{~d}$ of age was attained from all levels of restriction in female White Peking ducks fed with $80,60,40$ and $0 \%$ of ad libitum intake from 8 to $14 \mathrm{~d}$ of age. Tan and Ohtani (2000) reported that Peking ducks have similar body weight at $49 \mathrm{~d}$ of age when the ducks were fed ad libitum, 50\% of ad libitum, $50 \%$ rice hull-dilute feeding, and skip day feeding during 8 to $14 \mathrm{~d}$ of age. In current study, ducks was fed with diet diluted with $40 \%$ rice hull between 8 to $14 \mathrm{~d}$ of age. The body weight of RH40 ducks was lower than the RH0 ducks at $14 \mathrm{~d}$ of age. This may due to reduced growth rate of tissues during feed restriction (Hornick et al., 2000). The body weight of the RH40 ducks was close to the RH0 ducks at $42 \mathrm{~d}$ of age. This result indicated that full compensatory growth was obtained during 15 to $42 \mathrm{~d}$ of age, which is consistent to the previously mentioned reports (Tan et al., 1999; Tan and Ohtani, 2000). This observation suggested that diet dilution as a kind of restrict feeding in meat-type ducks might be available in practical application.

During the diet dilution period ( 8 to $14 \mathrm{~d}$ ), ducks in $\mathrm{RH}$
40 treatment consumed more $(p<0.05)$ feed and had greater $\mathrm{F}$ : $\mathrm{G}$ than ducks in RH0 treatment. This result was in agreement with Zubair and Leeson (1994), who reported that nutrition restricted chickens have high level feed intake relative to body weight. This result indicated that diluted diet was lower in nutrient and energy density than RH0 diet and ducks need to consume more feed to maintain body function. No difference was observed in FI ( $p>$ $0.05)$, but, $\mathrm{F}: \mathrm{G}$ was lower $(p<0.05)$ in $\mathrm{RH} 40$ treatment compared with the RH0 ducks during the re-alimentation period (15 to $42 \mathrm{~d}$ ). There was no difference in FI and $\mathrm{F}: \mathrm{G}$ between the RH0 and RH40 treatments $(p>0.05)$ during the overall period of the experiment (1 to $42 \mathrm{~d}$ ). These results showed that the diluted re-fed ducks gained more weight while consumed the same amount of feed with RH0 ducks during the period of re-feeding. Similarly, Tan and Ohtani (2000) reported that the diluted refed ducks enhanced digestion and absorption of nutrients compared with the control ducks after the period of diet dilution. It seems that the increased growth rate of diluted re-fed ducks in the present study could be partly due to better nutrient utilization, which may contribute to compensatory growth and improved feed efficiency.

Table 2. Effect of early diet dilution on growth performance in Peking ducks ${ }^{1}$

\begin{tabular}{lccc}
\hline \hline \multicolumn{1}{c}{ Item } & RH0 & RH40 & SE $^{2}$ \\
\hline Body weight, g & & & \\
d 7 & 223.2 & 223.5 & 2.3 \\
d 14 & $577.3^{\mathrm{a}}$ & $503.0^{\mathrm{b}}$ & 16.1 \\
d 42 & 2804.9 & 2813.4 & 13.6 \\
\hline \multicolumn{2}{c}{ Body weight gain, g } & & \\
d 8-14 & $354.1^{\mathrm{a}}$ & $279.5^{\mathrm{b}}$ & 8.8 \\
d 15-42 & $2227.6^{\mathrm{b}}$ & $2310.4^{\mathrm{a}}$ & 14.4 \\
d 1-42 & 2760.4 & 2768.9 & 12.0 \\
\hline Feed intake, g & & & \\
d 8-14* & $453.2^{\mathrm{b}}$ & $483.2^{\mathrm{a}}$ & 7.9 \\
d 8-14** & $453.2^{\mathrm{a}}$ & $289.9^{\mathrm{b}}$ & 6.8 \\
d 15-42 & 5612.4 & 5580.0 & 32.2 \\
d 1-42* & 6259.6 & 6257.2 & 35.8 \\
d 1-42** & $6259.6^{\mathrm{a}}$ & $6063.9^{\mathrm{b}}$ & 36.6 \\
\hline Feed : Gain & & & \\
d 8-14* & $1.28: 1^{\mathrm{b}}$ & $1.73: 1^{\mathrm{a}}$ & 0.02 \\
d 8-14** & $1.28: 1^{\mathrm{a}}$ & $1.04: 1^{\mathrm{b}}$ & 0.02 \\
d 15-42 & $2.52: 1^{\mathrm{a}}$ & $2.41: 1^{\mathrm{b}}$ & 0.01 \\
d 1-42* & $2.27: 1$ & $2.26: 1$ & 0.01 \\
d 1-42** & $2.27: 1^{\mathrm{a}}$ & $2.19: 1^{\mathrm{b}}$ & 0.01 \\
\hline RH0 0\% rice & &
\end{tabular}

${ }^{1} \mathrm{RH} 0,0 \%$ rice hull $\operatorname{diet} \AA^{\mathrm{a}} \mathrm{RH} 40,40 \%$ rice hull diet.

${ }^{2}$ Pooled standard error.

*feed intake and feed: gain, **adjusted feed intake and feed: gain (excluded the amount of rice hull).

a,b means with different superscripts in the same row are significantly different $(p<0.05)$. 
The adjusted feed intake (excluded rice hull) and $\mathrm{F}: \mathrm{G}$ (Table 2) in RH40 ducks were decreased $(p<0.05)$ compared with in RH0 ducks during 1 to $42 \mathrm{~d}$. This result indicated that the feed consumption was decreased when ducks were fed rice hull diluted diet. If we considering about the low price of rice hull, the improved feed efficiency would benefit the production of Peking ducks.

The live body weight of ducks was higher in RH0 treatment than those in RH40 treatment $(p<0.05)$ at $14 \mathrm{~d}$ of age. The weights of eviscerated carcass, breast meat, and leg meat in RH40 ducks were lower than in RH0 ducks at $14 \mathrm{~d}$ of age. The weight of skin with fat and abdominal fat in RH40 ducks was reduced $(p<0.05)$ compared with in RH0 ducks both at 14 and $42 \mathrm{~d}$ of age. The moisture content was increased $(p<0.05)$ in RH40 ducks compared with RH0 ducks at $14 \mathrm{~d}$ of age. The crude fat content was lower in RH40 ducks than in RH0 both at 14 and $42 \mathrm{~d}$ of age (Table 3).

At $14 \mathrm{~d}$ of age, the difference of live weight was significant $(p<0.05)$ between RH40 treatment and RH0 treatment. Similarly, weights of eviscerated carcass, breast and leg meat, skin with fat, abdominal fat and the crude fat content of carcass decreased $(p<0.05)$ in RH40 ducks compared with in RH0 ducks (Table 3). This result indicated that the growth rate of carcass, breast meat, leg meat, and abdominal fat were decreased in RH40 treatment compared with RH0 treatment. This phenomenon was confirmed by Hornick et al. (2000) who suggested that this may be due to reduced growth rate of tissues which caused by feed restriction. At $42 \mathrm{~d}$ of age, there was no difference in eviscerated carcass, breast and leg meat between the two treatment groups. This means that the contents of eviscerated carcass, breast meat and leg meat were recovered from early age diet dilution. However, the skin with fat, abdominal fat and the crude fat content of carcass were lower $(p<0.05)$ in RH40 ducks than in RH0 ducks. These results indicated that early diet dilution unaffected eviscerated carcass, breast and leg meat content. However, reduced carcass fat content in RH40 ducks compared with in RH0 ducks at $42 \mathrm{~d}$ of market age. It is likely that refeeding the basal diet after diet-diluted period allowed RH40 ducks to exhibit catch-up growth not only in body weight but also in muscle tissues. The finding of unaffected breast and leg meat content in current study was in consistent with Pinchasov et al. (1988) and Hayashi et al. (1990). Pinchasov et al. (1988) reported that feed deprivation caused a decrease in the breast muscle weight and re-feeding resulted in an increase in growth rate of breast muscles. Hayashi et al. (1990) showed that fasting re-feeding broiler chickens exhibited an increased rate of muscle protein turnover during the re-feeding period. The observation of uncompensated carcass fat content of this trial was in agreements with Plavnik and Hurwitz (1985); Cabel and Waldroup (1990); Tan and Ohtani (2000). Plavnik and Hurwitz (1985) noted that substantial reduction in the size of the abdominal fat pad of broilers was not influenced by nutrition during re-feeding. Cabel and Waldroup (1990) reported that reductions in abdominal fat pad could be attributed to early life feed dilution. Tan and Ohtani (2000) observed that early feed restriction reduced carcass fat content in male ducks fed diluted diet not only at the end of $7 \mathrm{~d}$ feed restriction but also at 49 of market age when

Table 3. Effect of early diet dilution ratio on carcass characteristics and chemical composition of Peking ducks at 14 and $42 \mathrm{~d}$ of age ${ }^{1}$

\begin{tabular}{|c|c|c|c|c|c|c|}
\hline \multirow{2}{*}{ Item $^{2}$} & \multicolumn{3}{|c|}{$14 \mathrm{~d}$} & \multicolumn{3}{|c|}{$42 \mathrm{~d}$} \\
\hline & RH0 & RH40 & $\mathrm{SE}$ & RH0 & RH40 & $\mathrm{SE}$ \\
\hline Live weigh, $\mathrm{g}$ & $569.3^{\mathrm{a}}$ & $500.7^{b}$ & 15.4 & 2810.0 & 2803.1 & 12.7 \\
\hline \multicolumn{7}{|l|}{ Carcass proflies $^{3}$} \\
\hline Eviscerated carcass & $70.21^{\mathrm{a}}$ & $68.42^{b}$ & 0.57 & 72.51 & 71.57 & 0.67 \\
\hline Breast meat & $3.09^{\mathrm{a}}$ & $2.54^{\mathrm{b}}$ & 0.09 & 10.70 & 10.61 & 0.18 \\
\hline Leg meat & $10.53^{\mathrm{a}}$ & $9.17^{b}$ & 0.16 & 8.00 & 7.95 & 0.10 \\
\hline Skin with fat & $15.62^{\mathrm{a}}$ & $13.93^{\mathrm{b}}$ & 0.11 & $23.57^{\mathrm{a}}$ & $20.34^{\mathrm{b}}$ & 0.22 \\
\hline Abdominal fat & $0.35^{\mathrm{a}}$ & $0.18^{\mathrm{b}}$ & 0.03 & $1.46^{\mathrm{a}}$ & $1.38^{\mathrm{b}}$ & 0.01 \\
\hline \multicolumn{7}{|l|}{ Chemical composition $^{4}$} \\
\hline Moisture & $67.3^{b}$ & $70.0^{\mathrm{a}}$ & 0.67 & 54.4 & 55.1 & 0.79 \\
\hline Crude fat & $13.3^{\mathrm{a}}$ & $10.1^{b}$ & 0.77 & $27.5^{\mathrm{a}}$ & $25.8^{b}$ & 0.5 \\
\hline Crude protein & 16.4 & 16.8 & 0.22 & 15.6 & 16.6 & 0.5 \\
\hline Crude ash & 3.0 & 3.1 & 0.2 & 2.5 & 2.5 & 0.2 \\
\hline
\end{tabular}

${ }^{1} \mathrm{RH} 0,0 \%$ rice hull diluted diet; $\mathrm{RH} 40,40 \%$ rice hull diluted diet.

${ }^{2}$ Pooled standard error.

${ }^{3}$ Expressed as the $\%$ of live weight.

${ }^{4}$ Expressed as the \% of carcass.

${ }^{\mathrm{a}, \mathrm{b}}$ Means with different superscripts in the same row are significantly different $(p<0.05)$. 
compared to controls. The crude fat contents of carcass at $14 \mathrm{~d}$ and $42 \mathrm{~d}$ of age are lower in RH40 treatment than in RH0 treatment $(p<0.05)$. This reduction of fat content may be due to fat mobilization for energy supply, and abdominal fat may be mobilized more easily during fasting period (Zhan et al., 2007). Hornick et al. (2000) also suggested that the adipose tissue react more sensitively than other tissues when animals are under feed restriction. Furthermore, this reduction of fat content could not be caught up until to marketing time. As ducks grew, the carcass moisture decreased and the carcass fat increased while the carcass protein was constant (Zhou et al., 2000). Peterson and Ellarson (1979) noted that moisture fraction in carcass generally varied opposite to lipids. The carcass moisture was increased $(p<0.05)$ in RH40 ducks compared with RH0 ducks due to the decreased content of fat at $14 \mathrm{~d}$ of age.

The hepatic adipose enzyme activities were shown in Table 4. The activities of MDH, G-6-PDH, and FAS were lower $(p<0.05)$ in $\mathrm{RH} 40$ treatment than in RH0 treatment both at 14 and $42 \mathrm{~d}$ of age.

In avian species, the liver is the major site for lipogenesis and bone marrow, and adipose tissue and skin make minor contributions (Zhong et al., 1995). It has been reported that hepatic lipogenesis is highly responsive to nutrient changes in diets, the nutritional state of the bird as well as the amount and composition of feed consumed (Hillgartner et al., 1995).

Zhou et al. (2000) confirmed that MDH and G-6-PDH are two NADPH-generating primary enzymes for the support of lipogenesis in growing Peking ducks. FAS is a major biosynthetic enzyme for fatty acid synthesis. A high expression of FAS mRNA was related to increased triglyceride depot in muscle tissue of Pekin ducks (Saez et al., 2009). Rosebrough et al. (1986) showed that early feed restriction in broiler chickens resulted in a decrease body fat content without reducing the general performance at market age.

In the present study, these hepatic lipogenic enzyme activities were determined to reveal the mechanism of different carcass fat content (Table 4). At the end of diet dilution period (14 $\mathrm{d}$ of age), the activities of G-6-PDH, MDH and FAS in liver of feed-restricted ducks were decreased $(p<$ $0.05)$ with compared with the control, and the differences $(p<0.05)$ were standing until the end of the experiment (42 d of age). These phenomena of continual reduced hepatic adipose enzyme activities by early diet diluted in birds had reported in many literatures. Rosebrough et al. (1986) observed reductions in both liver size and lipogenesis in $12 \mathrm{~d}$-old broiler subjected to feed dilution from 6 to $12 \mathrm{~d}$.
Table 4. Effects of early diet dilution on hepatic adipose enzyme activities in Peking ducks at $14 \mathrm{~d}$ and $42 \mathrm{~d}$ of age $\mathrm{e}^{1}$

\begin{tabular}{ccccccc}
\hline \hline & \multicolumn{3}{c}{$14 \mathrm{~d}$} & & \multicolumn{3}{c}{$42 \mathrm{~d}$} \\
\cline { 2 - 7 } Item $^{2}$ & \multirow{2}{*}{ MDH } & $\begin{array}{c}\text { G-6- } \\
\text { PDH }\end{array}$ & FAS & MDH & $\begin{array}{c}\text { G-6- } \\
\text { PDH }\end{array}$ & FAS \\
\hline RH0 & $240.0^{\mathrm{a}}$ & $125.0^{\mathrm{a}}$ & $59.4^{\mathrm{a}}$ & $288.4^{\mathrm{a}}$ & $176.0^{\mathrm{a}}$ & $78.4^{\mathrm{a}}$ \\
RH40 & $188.2^{\mathrm{b}}$ & $83.5^{\mathrm{b}}$ & $44.7^{\mathrm{b}}$ & $240.1^{\mathrm{b}}$ & $121.1^{\mathrm{b}}$ & $63.9^{\mathrm{b}}$ \\
$\mathrm{SE}^{3}$ & 25.4 & 18.0 & 10.5 & 24.9 & 19.2 & 14.7 \\
\hline
\end{tabular}

${ }^{1} \mathrm{MDH}$, malic dehydrogenase; G-6-phosphate dehydrogenase; FAS, fatty acid synthetase. The unit of enzyme activity was express as nmol per min per mg protein.

${ }^{2} \mathrm{RH} 0,0 \%$ rice hull diluted diet; RH40, $40 \%$ rice hull diluted diet. ${ }^{3}$ Pooled standard error.

${ }^{a, b}$ Means with different superscripts in the same column are significantly different $(p<0.05)$.

Zhong et al. (1995) found the rate of lipogenesis was lower in early feed restricted than ad libitum broiler chickens up to $54 \mathrm{~d}$ of age. Tan and Ohtani (2000) fed ducks with diluted diet containing about $50 \%$ rice hull between 8 to $14 \mathrm{~d}$ of age, carcass fat contents decreased at 14 and $49 \mathrm{~d}$ of age, the activities of hepatic fatty acid synthetase (FAS) and acetyl-CoA carboxylase (ACC) decreased at the end of $7 \mathrm{~d}$ feed restriction and tended to further decrease at $49 \mathrm{~d}$ of age, when compared with control $(0 \%$ rice hull). Tan et al. (1999) reported that the carcass fat content in meat-type female ducks at $47 \mathrm{~d}$ of age was not different between control $(0 \%$ rice hull) and feedrestricted treatment ( $50 \%$ rice hull). These phenomena of continual suppressed carcass fat content by early feed restriction in birds might be interpreted hepatic adipose metabolic programming although it has been reported that carcass fat content of ducks was sensitive to change in amount of feed intake at a later stage of growth (Campbell et al., 1985).

Generally speaking, there has two pathways to regulate the activity of lipogenesis enzymes: hormones that communicate changes in nutritional status to the liver and other organs such as insulin, 3,5,3'-triiodothyronine and glycogen (Goodridge et al., 1986; Hillgarter et al., 1995; Stapleton et al., 1990) that could affect the lipogenesis enzymes; the glucose level in blood alternate the hepatic function (Gifforn-Katz and Katz, 1986; Mariash and Oppenheimer, 1984; Molero et al., 1993; Prip-Buus et al., 1995). The activities of MDH, G-6-PDH and FAS were inhibited throughout the experimental period. This may be explained by a theory that early age malnutrition sometimes could permanently alter the metabolism of an animal in the absence of the malnutrition stress (Wells et al., 2007).

Collectively, ducks subjected to diet dilution with $40 \%$ 
rice hull during 8 to $14 \mathrm{~d}$ of age fully recovered body weight and meat yield at $42 \mathrm{~d}$ of age, effectively improved feed efficiency in the whole period of experiment, and obviously reduced carcass fat deposition and hepatic lipogenic enzyme activities in meat-type ducks at $14 \mathrm{~d}$ of age, and up to market age. The continual suppressed hepatic lipogenic enzyme activities in re-fed period might be the prolonged programming of lipid metabolize. The programming could partly explain the decreased fat accumulation in carcass.

\section{Acknowledgements}

This research was financially supported by the Natural Science Foundation of Hubei Province, China (Project No. 2010CBB02901). The authors would like to thank X. J. Li for his assistance in the determination of enzyme activities.

\section{References}

1. AOAC. (1984) Official Methods of Analysis, 14th ed. Arlington (VA, USA): Association of Official Analytical Chemists.

2. Bergmeyer, H. U., Bergmeyer, J., and Grassl, M. (1974) Methods of Enzymatic Analysis: Glucose-6-phosphate dehydrogenase. 3 ed. Academic Press, New York.

3. Cabel, M. C. and Waldroup, P. W. (1990) Effect of different nutrition-restricted programs early in life on broiler performance and abdominal fat content. Poultry Sci. 69: 652-660.

4. Campbell, R. G., Karunajeewa, H., and Bagot, L. (1985) Influence of food intake and sex on the growth and Carcass composition of Peking ducks. Brit. Poultry Sci. 26: 43-50.

5. Colowick, S. P. and Kaplan, N. O. (1955) Methods in Enzymology: Malic enzyme. Academic Press, New York.

6. Gibson, D. M., Lyons, R. T., Scott, D. F., and Muto, Y. (1972) Synthesis and degradation of the lipogenic enzymes of rat liver. Adv. Enzyme Regul. 10: 187-204.

7. Gifforn-Katz, S. and Katz, N. R. (1986) Carbohydrate-dependent induction of fatty acid synthase in primary cultures of rat hepatocytes. Eur. J. Biochem. 159: 513-158.

8. Goodridge, A. G., Back, D. W., Wilson, S. B., and Goldman, M. J. (1986) Regulation of genes for enzymes involved in fatty acid synthesis. Ann. NY. Acad. Sci. 478: 46-62.

9. Hassanabadi, A. and Nassiri, M. H. (2006) Effect of early feed dilution on performance characteristics and serum thyroxin of broiler chickens. Int. J. Poult. Sci. 5: 1156-1159.

10.Hayashi, K., Nakano, M., Toyomizu, M., Tomita, Y., Iwamoto, T., and Shika, A. (1990) Effect of fasting early in life on performance, mortality and muscle protein metabolism of broiler chicken in high temperature environment. Jpn. J. Zootech. Sci. 61: $264-270$.

11. Hillgartner, F. B., Salati, L. M., and Goodridge, A. G. (1995) Physiological and molecular mechanisms involved in nutritio- nal regulation of fatty acid synthesis. Physiol.Rev. 75: 47-76.

12. Hornick, J. L., van Eenaeme, C., Gerard, O., Dufrasne, I., and Istasse, L. (2000) Mechanism of reduced and compensatory growth. Domest. Anim. Endocrin. 19:121-132.

13. Jones, G. P. and Farrell, D. J. (1992) Early-life food restriction of broiler chickens. I. Methods of application, amino acid supplementation and the age at which restrictions should commence. Brit. Poultry Sci. 33: 579-587.

14. Knizetova, H., Hyanek, J., Knize, B., and Prochazkova, H. (1991) Analysis of growth curves of fowl. II. Ducks. Brit. Poultry Sci. 32: 1039-1053.

15. Leeson, S., Summers, J. D., and Proulx, J. (1982) Production and carcass characteristics of the duck. Poultry Sci. 61: 24562464.

16. Lucas, A. (1998) Programming by early nutrition: An experimental approach. J. Nutr. 128: 401S-406S.

17. Mariash, C. N. and Oppenheimer, J. H. (1984) Stimulation of malic enzyme formation in hepatocyte culture by metabolites: Evidence favoring a nonglycolytic metabolite as the proximate induction signal. Metablolism 33: 545-552.

18. Ministry of Agriculture of China. (2004) Feeding standard of chicken. Standards Press of China, Beijing, China.

19. Molero, C., Benito, M., and Lorenzo, M. (1993) Regulation of malic enzyme gene expression by nutrients, hormones, and growth factors in fetal hepatocyte primary cultures. J. cell Physiol. 155: 197-203.

20. Nielsen, B. L., Litherland, M., and Noddegaard, F. (2003) Effect of qualitative and quantitative feed restriction on the activity of broiler chickens. Appl. Anim. Behav. Sci. 83: 309-323.

21. NRC. (1994) Nutrient requirements of Poultry. 9th ed., National Academy Press, Washington, D. C.

22. Patel, M. S. and Srinivasan, M. (2002) Metabolic programming: Causes and consequences. J. Biol. Chem. 277: 1629-1632.

23. Peterson, S. R. and Ellarson, R. S. (1979) Changes in oldsquaw carcass weitght. Wilson Bull. 91(2): 288-300.

24. Pinchasov, Y., Nir, I., and Nitsan, Z. (1988) The synthesis in vivo of protein in various tissues in chickens adapted to intermittent feeding. Brit. J. Nutr. 60: 517-523.

25. Plavnik, I. and Hurwitz, S. (1985) The performance of broiler chickens during and following a severe feed dilution at an early age. Poultry Sci. 64: 348-355.

26. Plavnik, I., Hurwitz, S., and Barash, H. (1982) The effect of feed restriction on the growth, feed conversion and fattening of Pekin ducks. Nutr. Rep. Intern. 25: 907-911.

27. Prip-Buus, C., Perdereau, D., Foufelle, F., Maury, J., Ferre, P., and Girard, J. (1995) Induction of fatty-acid-synthase gene expression by glucose in primary culture of rat hepatocytes. Dependency upon glucokinase activity. Eur. J. Biochem. 230: 309-315.

28. Rezaei, M., Teimouri, A., Pourreza, J., Syyahzadeh, H., and Waldroup, P. W. (2006) Effect of diet dilution in the starter period on performance and carcass characteristics of broiler chickens. Journal of Central European Ag. 7: 63-70.

29. Rosebrough, R. W., Steel, N. C., Mcmurtry, J. P., and Plavnik, I. (1986) Effect of early feed restriction in broiler. II. Lipid metabolism. Growth 50: 217-227. 
30. Saez, G., Davail, S., Gentes, G., Hocquette, J. F., Jourdan, T., Degrace, P., and Baeza, E. (2009) Gene expression and protein content in relation to intramuscular fat content in Muscovy and Pekin ducks. Poultry Sci. 88: 2382-2391.

31. SAS. (2000) SAS/STAT Software for PC. Release 8.1, SAS Institute Inc., Cary, NC, USA.

32. Stapleton, S. R., Mitchell, D. A., Salati, L. M. and Goodridge, A. G. (1990) Triiodothyronine stimulates transcription of the fatty acid synthase gene in chick embryo hepatocytes in culture. Insulin and insulin-like growth factor amplify that effect. $J$. Biol. Chem. 265: 18442-18446.

33. Tan, B. J. and Ohtani, S. (2000) Effect of different early feed restriction regimens on performance, carcass composition, and lipid metabolism in male ducks. Anim. Sci. J. 71: 586-593.

34. Tan, B. J., Ohtani, S., and Tanaka, K. I. (1999) Effect of early feed restriction of varied severity on growth performance, carcass composition and lipid metabolism in female ducks. Anim. Sci. J. 70: 297-305.

35. Wells, J. C. K., Chomto, S., and Fewtrell, M. S. (2007) Programming of body composition by early growth and nutrition. P. Nutr.Soc. 66: 423-434.
36. Zhan, X. A., Wang, M., Ren, H. R., Zhao, Q. J., Li, X., and Tan, Z. L. (2007) Effect of early feed restriction on metabolic programming and compensatory growth in broiler chickens. Poultry Sci. 86: 654-660.

37. Zhong, C., Nakaue, H. S., Hu, C. Y., and Mirosh, L. W. (1995) Effect of full feed and early feed restriction on broiler performance, abdominal fat level, cellularity, and fat metabolism in broiler chickens. Poultry Sci. 74: 1636-1643.

38. Zhou, C. H., Ohtani, S., and Tanaka, K. I. (2000) Carcass composition parts proportion and fat deposition of meat-type growing ducks. Jpn. Poult. Sci. 37: 357-364.

39. Zubair, A. K. and Leeson, S. (1994) Effect of early feed restriction and realimentation on heat production and changes in size of digestive organs of male broilers. Poultry Sci. 73: 529538.

40. Zubair, A. K. and Leeson, S. (1996) Changes in body composition and adipocyte cellularity of male broilers subjected to varying degrees of early-life feed restriction. Poultry Sci. $\mathbf{7 5}$ : 719-728.

(Received 2013.3.14/Revised 2013.4.22/Accepted 2013.6.3) 